\title{
Catalytic effect of biomass leachate on high rank coal gasification and char structure evolution
}

\section{Supplemental Materials}

Fig. S1 FTIR spectroscopy for coal chars

Fig. S2 DTG curves of raw and water washed biomass (CSW: washed CS; CC: washed CC) Fig. S3 Detailed schematic of TGA

Fig. S4 SEM images of coal char and gasified semi-char 


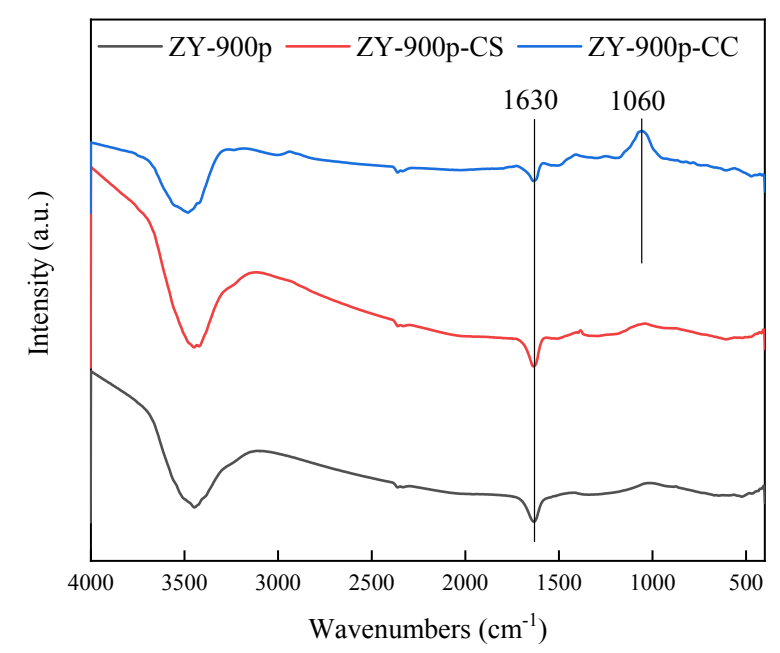

Fig. S1 FTIR spectroscopy for coal chars

The absorption frequency of aromatic $\mathrm{C}=\mathrm{C}$ stretching vibration is approximately 1600 $\mathrm{cm}^{-1}$ [1]. Specially, an evident peak intensity of signals at $1060 \mathrm{~cm}^{-1}$, which mainly assigned to the aromatic skeletal and C-O stretch [2], can be seen from the spectra of ZY-900p-CC. It indicated that the organic matter attached to the coal char surface.

[1] Niu Z, Liu G, Yin H, Wu D, Zhou C. Investigation of mechanism and kinetics of nonisothermal low temperature pyrolysis of perhydrous bituminous coal by in-situ FTIR. Fuel 2016;172:1-10.

[2] Zheng A, Zhao K, Li L, Zhao Z, Jiang L, Huang Z, et al. Quantitative comparison of different chemical pretreatment methods on chemical structure and pyrolysis characteristics of corncobs. Journal of the Energy Institute 2018;91(5):676-82. 


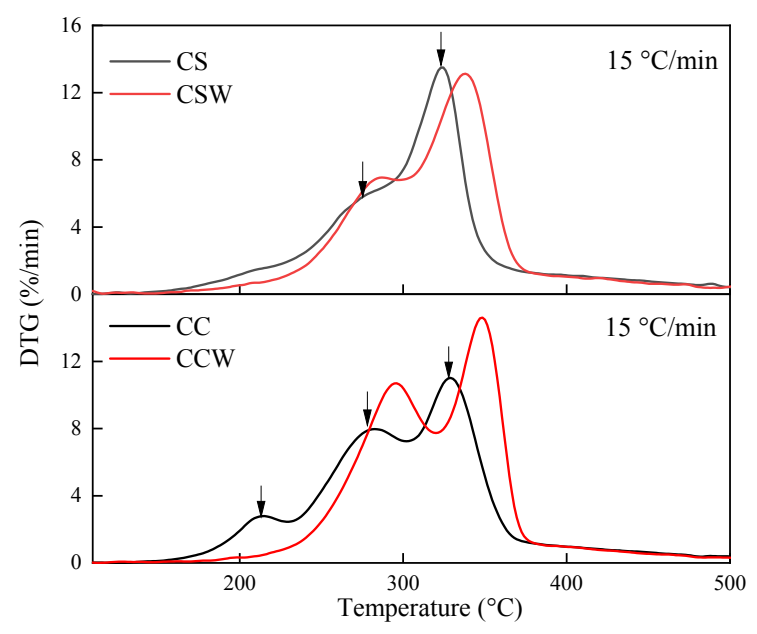

Fig. S2 DTG curves of raw and water washed biomass (CSW: washed CS; CC: washed CC)

The two distinguish DTG peak of CS/CSW pyrolysis can be observed, corresponding to the decomposition of hemicellulose and cellulose. Whereas three peaks were observed for CC pyrolysis. The peak at the lowest temperature in $\mathrm{CC}$ pyrolysis should be the decomposition of pectin, which was a regular constituent of corncob [1]. However, the DTG peak of the washed biomass shifted to the higher temperature range. And specially, the peak of pectin decomposition disappeared for $\mathrm{CCW}$ pyrolysis. It suggested that the $\mathrm{CC}$ leachate contained much more organics, which can be attach to the coal char surface during the leaching pretreatment.

[1] Trninić M, Wang L, Várhegyi G, Grønli M, Skreiberg Ø. Kinetics of Corncob Pyrolysis. Energ Fuel 2012;26(4):2005-13. 


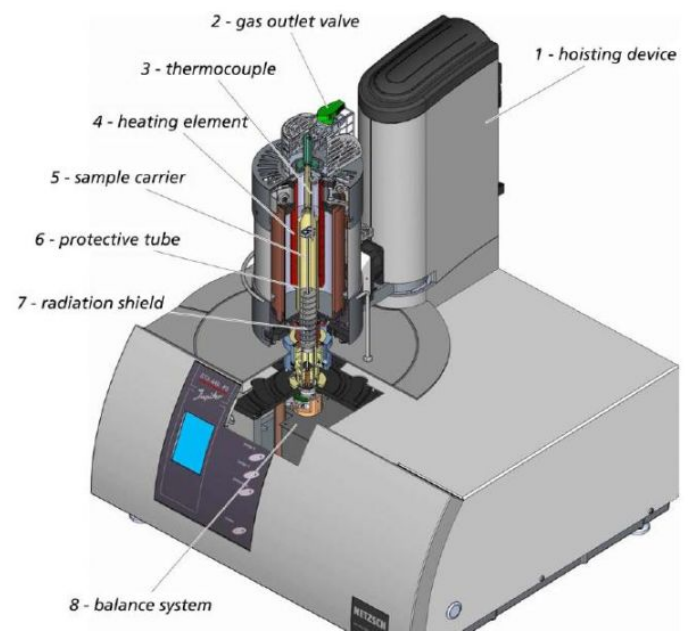

Fig. S3 Detailed schematic of TGA 


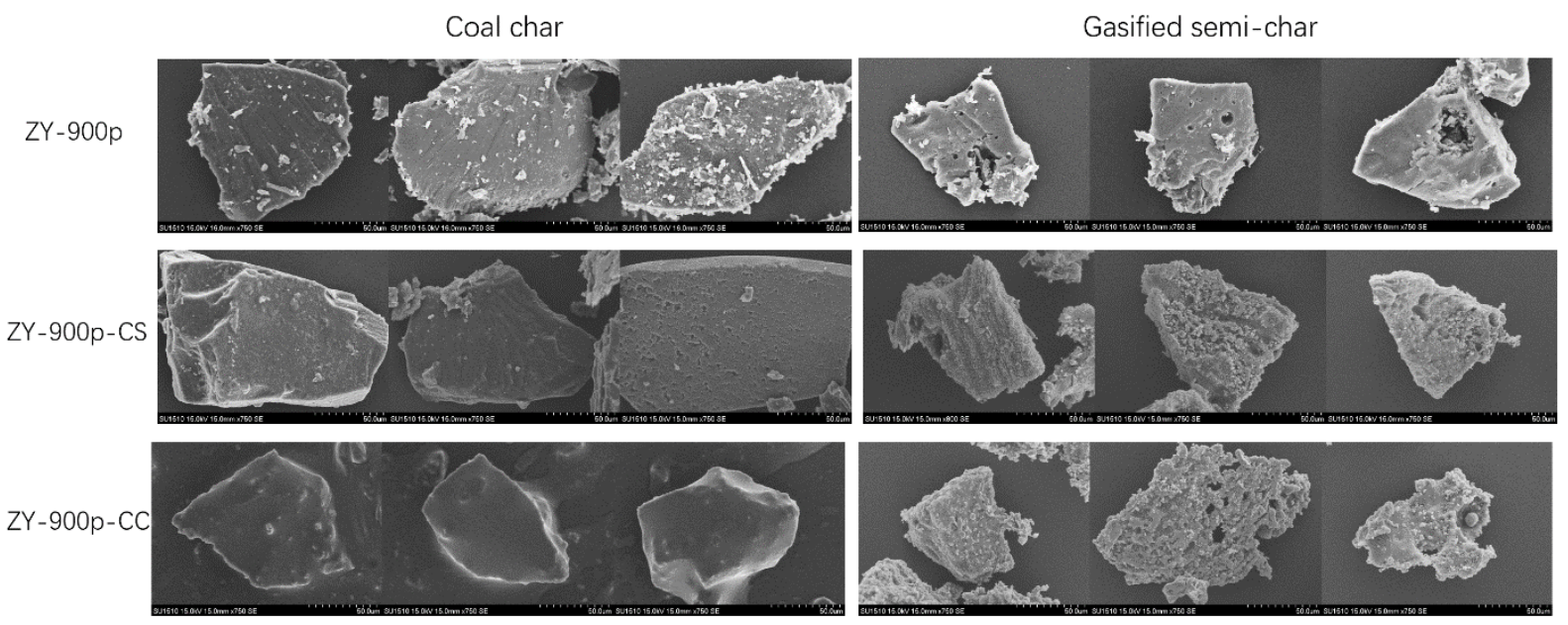

Fig. S4 SEM images of coal char and gasified semi-char 